\title{
In vitro effect of fosfomycin on multi-drug resistant gram-negative bacteria causing urinary tract infections
}

This article was published in the following Dove Press journal: Infection and Drug Resistance

\author{
Pallam Gopichand' \\ Girija Agarwal ${ }^{2}$ \\ Mailan Natarajan' \\ Jharna Mandal ${ }^{1}$ \\ Surendran Deepanjali ${ }^{3}$ \\ Sreejith Parameswaran ${ }^{4}$ \\ LN Dorairajan ${ }^{5}$ \\ 'Department of Microbiology, Jawaharlal \\ Institute of Postgraduate Medical \\ Education \& Research (JIPMER), \\ Pondicherry, India; ${ }^{2}$ Jawaharlal Institute of \\ Postgraduate Medical Education \& \\ Research (JIPMER), Pondicherry, India; \\ ${ }^{3}$ Department of Medicine, Jawaharlal \\ Institute of Postgraduate Medical \\ Education \& Research (JIPMER), \\ Pondicherry, India; ${ }^{4}$ Department of \\ Nephrology, Jawaharlal Institute of \\ Postgraduate Medical Education \& \\ Research (JIPMER), Pondicherry, India; \\ ${ }^{5}$ Department of Urology, Jawaharlal \\ Institute of Postgraduate Medical \\ Education \& Research (JIPMER), \\ Pondicherry, India
}

Correspondence: Jharna Mandal Department of Microbiology, Jawaharlal Institute of Postgraduate Medical Education \& Research (JIPMER),

Pondicherry, India

Tel +9l 9677451239

Email drjharna@gmail.com
Background: Rising rates of resistance to antimicrobial drugs among Enterobacteriaceae limit the choice of therapeutic agents to treat urinary tract infections. In this context we assessed the invitro effect of fosfomycin against extended-spectrum beta-lactamases, AmpC beta-lactamases and carbapenemase-producing strains of Escherichia coli, Klebsiella pneumoniae, Enterobacter spp, and Pseudomonas aeruginosa isolated from the patients with urinary tract infection (UTI) and also studied the effect of fosfomycin on their biofilm formation.

Materials and methods: A total of 326 multidrug-resistant (MDR) isolates comprising of Escherichia coli, Klebsiella pneumoniae, Enterobacter spp, and Pseudomonas aeruginosa from the urine samples of the patients with a diagnosis of UTI were included in the study. MIC 50 and MIC 90 were detected by agar dilution method and the capacity to form biofilm in the presence of fosfomycin by these MDR isolates was assessed by the tissue culture plate method.

Results: The MIC50 for meropenem $(0.5 \mu \mathrm{gm} / \mathrm{mL})$ and nitrofurantoin $(32 \mu \mathrm{gm} / \mathrm{mL})$ was within the susceptible range only for E. coli. Fosfomycin was the only antibiotic that inhibited 100\% E.coli, 70\% Klebsiella spp, and 50\% Pseudomonas spp and 40\% Enterobacter spp which included the extended-spectrum beta-lactamases producers. It showed a similar effect on carbapenemase producers and AmpC producers. Fosfomycin disrupted biofilm in 67\% ( $\mathrm{n}=141)$ E.coli, 74\% (n=50) Klebsiella spp, 88\% ( $\mathrm{n}=27)$ Pseudomonas spp and 36\% $(\mathrm{n}=23)$ Enterobacter spp at $24 \mathrm{hrs}$ of incubation with a concentration of 2 fold dilution lower than that of the MIC.

Conclusion : Fosfomycin showed a good inhibitory effect on the biofilms produced by the MDR organisms studied here.

Keywords: fosfomycin, MDR, UTI, MIC, biofilm

\section{Introduction}

The most common cause of all forms of UTIs is Escherichia coli (uropathogenic Escherichia coli), followed by other members of Enterobacteriaceae like Klebsiella, Proteus, Enterobacter spp and other gram positives like Enterococci and Staphylococcus spp. ${ }^{1}$

Urinary tract infections caused by drug-resistant Enterobacteriaceae have been on the rise. ${ }^{2}$ The emergence of the multidrug-resistant (MDR) strains with either inherited or transmissible resistance, is resistant to most of the commonly used antibiotics has become a concern for treating UTI, both in the community as well as the hospital. ${ }^{2}$

The most disconcerting events are the UTIs caused by Carbapenemase-producing Enterobacteriaceae which are difficult-to-treat and are usually characterized 
by high mortality. ${ }^{3}$ Many MDR pathogens are also known to produce biofilms in catheterized patients which are extremely difficult to treat. ${ }^{4}$ In this era of increasing antimicrobial resistance, there is definitely a need for a newer drug that is orally active, has low levels of existing resistance and also has an effect on biofilms. Fosfomycin is a relatively old drug and the present study was conducted to determine the effect of fosfomycin on MDR pathogens as well as its effect on biofilm formation by these isolates.

Oral single-dose fosfomycin is considerably effective for the treatment of uncomplicated urinary tract infection. ${ }^{5}$ Other traditional empirical antibiotic regimens which are commonly used for treating uncomplicated urinary tract infections, such as fluoroquinolones and co-trimoxazole, might be not active against these pathogens that produce ESBL and can lead to suboptimum outcomes and treatment failure. ${ }^{6}$ Apart from fosfomycin, nitrofurantoin, and coamoxiclav could be other options for oral antimicrobial treatment of ESBL-associated but otherwise uncomplicated urinary tract infections. Furthermore, because of its unique chemical structure and mechanism of action, fosfomycin seems to be spared from the effect of various mechanisms of resistance to antimicrobial drugs. Apart from the Enterobacteriaceae that produce ESBL, the very good antimicrobial effect of fosfomycin has also been reported in Enterobacteriaceae that are resistant to fluoroquinolones. Due to its improved pharmacokinetics, fosfomycin is increasingly used for UTIs and has been approved as an oral single-dose treatment for acute uncomplicated cystitis with mean peak urinary concentration of an oral single dose of $3 \mathrm{~g}$ fosfomycin tromethamine, while concentrations sufficient to inhibit the majority of the urinary pathogens can be maintained for 1 to 2 days. Though this easy dosage schedule ensures compliance but the chance of clinical cure may be compromised. ${ }^{7}$

\section{Materials and methods Study design}

The study was conducted in Jawaharlal Institute of Postgraduate Medical Education \& Research (JIPMER) which is a tertiary care referral center, an Institute of National Importance under the Ministry of Health and Family Welfare, Government of India. Urinary isolates from the in-patients with clinically diagnosed UTI (dysuria, frequency, urgency, suprapubic tenderness, the presence of pus cells in urine/high power field) admitted in the departments of Medicine, Nephrology, and Urology were included.

\section{Inclusion criteria}

All first fifty consecutive, nonrepetitive MDR isolates in a month for a period of one year (2016-2017) from the urine obtained from these patients admitted in the respective departments were included in the study. Only a single isolate from the first sample submitted in the laboratory was included from the patient. The demographic details and comorbid conditions of the respective patients were collected prospectively in a prescribed proforma.

\section{Exclusion criteria}

Pediatric patients (upto $13 \mathrm{yrs}$ ) were not included in the study.

\section{Microbiological methods}

The specimens were processed using the standard semiquantitative culture method and isolates were biochemically characterized by using indole production, citrate utilization, urease production, kligler iron agar, mannitol fermentation and motility test medium, lysine and ornithine decarboxylases, arginine hydrolysis tests were used as described elsewhere. ${ }^{8,9}$ Standard American type culture collection (ATCC) control strains (E. coli ATCC 25922, and P. aeruginosa ATCC 27853) within acceptable limits were used as quality control strains for the drugs tested. Susceptibility testing for amikacin, gentamicin, nitrofurantoin, ceftriaxone, ceftazidime, meropenem, andfosfomycin were performed as per the Clinical Laboratory Standards Institute. ${ }^{10}$ All the isolates identified as multi-drug resistant based on the criteria of the European Centre for Disease Control (nonsusceptible to $\geq 1$ agent in $\geq 3$ antimicrobial categories) were tested with fosfomycin. ${ }^{10}$ The MIC of all isolates to the drugs included in the study was determined by the agar dilution method. For susceptibility testing by the agar dilution method, Mueller-Hinton agar with serial two-fold dilution of the drug was prepared from the stock antibiotic solution as described by CLSI. ${ }^{10}$ For fosfomycin susceptibility testing by the agar dilution method, Mueller-Hinton agarsupplemented with $25 \mu \mathrm{g} / \mathrm{mL}$ of glucose-6-phosphate was used. The MIC of each antimicrobial agent was defined as the lowest concentration that inhibited the visible growth of the organism. Control strains, including E. coli ATCC 25922, and P. aeruginosa ATCC 27853, were included in each set of tests. The MIC of the fosfomycin were noted based on both CLSI $(\mathrm{S} \leq 64, \mathrm{I}=128$. $\mathrm{R}>256)$ guidelines for Escherichia colisince, CLSI do not prescribe any criteria for Pseudomonas aeruginosa and Enterobacteriaceae 
other than Escherichia coli, EUCAST interpretative criteria $(\mathrm{S} \leq 32, \mathrm{R}>32)$ for all isolates of Enterobacteriaceae and Pseudomonas aeruginosa other than Escherichia colim were used. $^{10,11}$ The various beta-lactamases namely, the ESBL, AmpC, and MBL were screened using the combination discs. ESBL producers were detected by using combination discs of ceftriaxone, ceftazidime and clavulanic acid. AmpC producers were detected by cefoxitin-EDTA disk diffusion test while MBL producers were detected by Double-disk synergy test (DDST). ${ }^{10}$

Biofilm formation of this MDR isolates wasperformed by tissue culture plate method described by Christensen et $\mathrm{al}^{12}$. Briefly, the isolates from fresh agar plates were inoculated in Trypticasesoya broth (TSB) media and incubated for $18 \mathrm{hrs}$ at $37{ }^{\circ} \mathrm{C}$ in a stationary condition and diluted 1 in 100 with fresh TSB medium. Individual wells of sterile, polystyrene, 96 well-flat bottom tissue culture plate were filled with $0.2 \mathrm{~mL}$ aliquots of the diluted cultures and only broth without culture is used as a control to check sterility and non-specific binding of media. The tissue culture plates were incubated for $16 \mathrm{hrs}$ and $24 \mathrm{hrs}$ at $37^{\circ} \mathrm{Cseperately.} \mathrm{After} \mathrm{incubation,} \mathrm{the}$ content of each well was gently removed by tapping the plates. The wells were washed four times with $0.2 \mathrm{~mL}$ of phosphate buffer saline (PBS pH 7.2) to remove free-floating "planktonic" bacteria. Biofilms formed by adherent "sessile" organisms in the plate were fixed with sodium acetate $(2 \%)$ and stained with crystal violet $(0.1 \% \mathrm{w} / \mathrm{v})$. The excess stain was rinsed off by thorough washing with deionized water and plates were kept for drying. Optical density (OD) of stained adherent bacteria was determined with a micro ELISA auto reader at a wavelength of $570 \mathrm{~nm}$ (OD $570 \mathrm{~nm}$ ). These OD values were considered as an index of bacteria adhering to surface and forming biofilms. The experiment was performed in triplicate and the data were averaged and the standard deviation was calculated. To compensate for background absorbance, OD readings from sterile medium, fixative, and dye were averaged and subtracted from all test values. Then the values obtained from with and without fosfomycin were compared. The mean OD value obtained from media control well was deducted from all the test OD values. This was done in the presence of fosfomycin and without fosfomycin. Fosfomycin was used at a concentration below twofold the level of MIC of different isolates.

\section{Statistical analysis}

The stastical analysis was performed using SPSS software 19.0 version. The distribution of categorical data such as gender, clinical characteristics, antibiotic resistance profile,
MDR isolates, and biofilm inhibition status was expressed as frequency and percentage. The association of the isolates on biofilm inhibition status at different time periods was carried out by using a chi-square test. The change in the biofilm inhibition status over time was carried out by using McNemar's test. All statistical analyses were carried out at $5 \%$ level of significance and $p$-value $<0.05$ was considered significant.

\section{Results}

Among these MDR organisms isolated from the patients, catheterization was the most common risk factor followed by diabetes mellitus, renal calculi and Urological surgical procedures (Table 1). MIC50 for meropenem $(0.5 \mu \mathrm{gm} / \mathrm{mL})$ and nitrofurantoin $(32 \mu \mathrm{gm} / \mathrm{mL})$ was within the susceptible range only for E. coli (Table 2). On the other hand, fosfomycin was the only antibiotic that good inhibitory effect on E.coli, Klebsiella, andamoderate effect on Pseudomonas spp and Enterobacter spp which included the extendedspectrum beta-lactamases producers, carbapenemase producers and AmpC producers with (Tables 3,4). Fosfomycin disrupted biofilm better at $24 \mathrm{hrs}$ of incubation in E.coli at a concentration of $0.5 \mu \mathrm{gm} / \mathrm{mL}$ and in Klebsiella spp, Pseudomonas spp and Enterobacter spp at a concentration of $8 \mu \mathrm{gm} / \mathrm{mL}$. The difference of inhibition of biofilm formation in Escherichia coli and K.pneumoniae, and Pseudomonas spp at $16 \mathrm{hrs}$ and at $24 \mathrm{hrs}$ was statistically significant $(P$-value $<0.0001)$ (Table 5).

\section{Discussion}

A sum total of 326 non-repetitive MDR isolates was collected and subjected to MIC. Out of 326 isolates, 231 (73.4\%) were from patients admitted under Medicine, 73 (21\%) were from Urology and 22 (6\%) were from Nephrology.

In the present study, we assessed the effect of fosfomycin in gram-negative MDR urinary isolates. E.coli was the most common isolate among all the MDR isolates

Table I The underlying comorbid conditions in the study group

\begin{tabular}{|l|l|l|l|}
\hline $\begin{array}{l}\text { S } \\
\text { no }\end{array}$ & $\begin{array}{l}\text { Underlying co-morbid } \\
\text { factors }\end{array}$ & $\begin{array}{l}\text { Number } \\
\text { of } \\
\text { patients }\end{array}$ & Percentage \\
\hline 1 & Renal calculi & 132 & $43.7 \%$ \\
2 & Diabetes mellitus & 142 & $47.0 \%$ \\
3 & Urological surgical procedures & 62 & $20.5 \%$ \\
4 & Catheterization & 145 & $48.0 \%$ \\
\hline
\end{tabular}




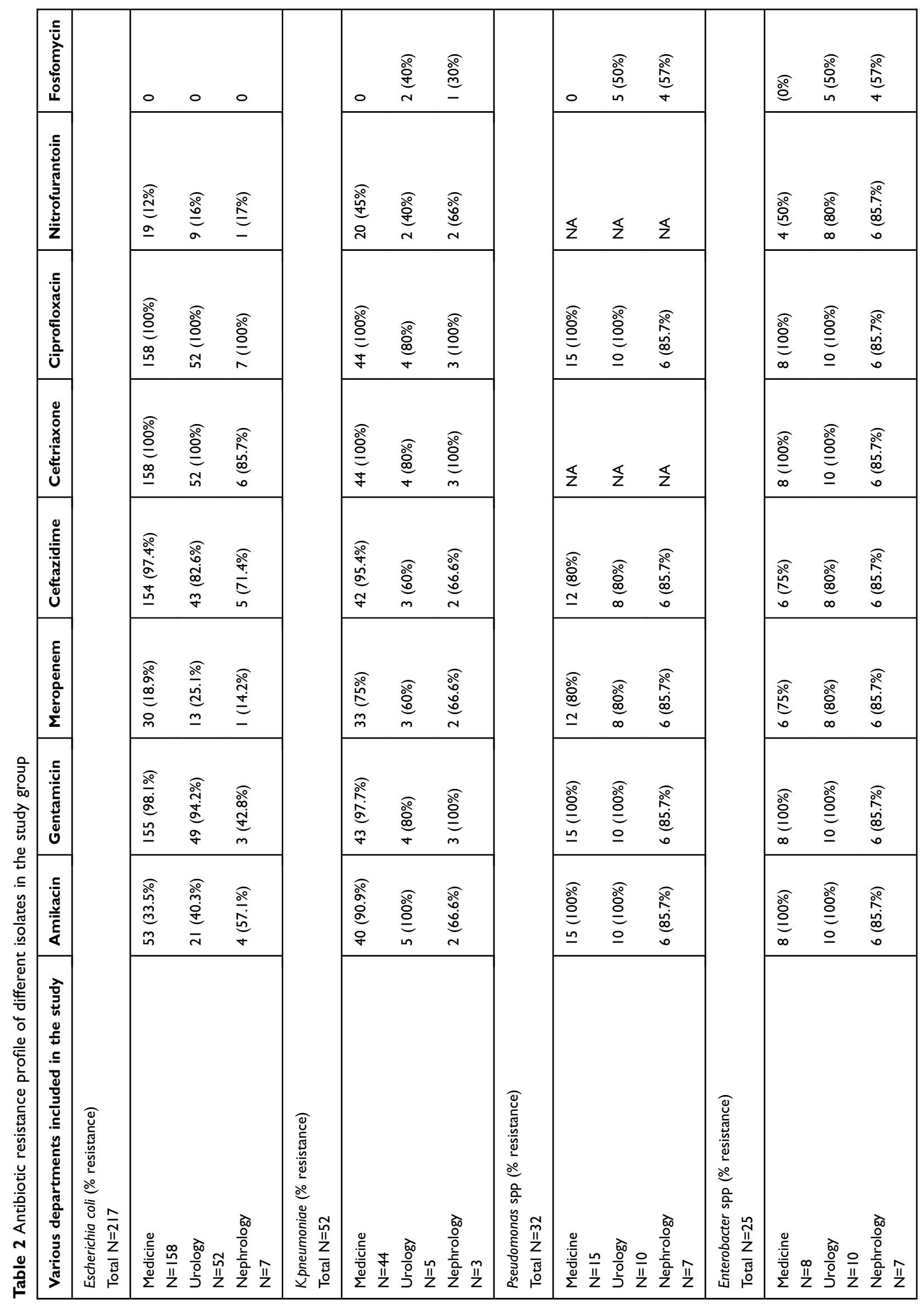


Table 3 Mechanism of beta-lactam resistance detected by phenotypic methods and effect of fosfomycin on different beta-lactam resistant isolates

\begin{tabular}{|c|c|c|c|c|c|c|c|}
\hline \multirow{2}{*}{$\begin{array}{l}\text { Mechanism of beta-lactams } \\
\text { resistance detected phenotypically } \\
\text { MIC of fosfomycin }[\mu \mathrm{gm} / \mathrm{mL}]\end{array}$} & \multicolumn{7}{|c|}{$\begin{array}{l}\text { Isolates with visible growth at different concentration of fosfomycin and (\%) resistance o } \\
\text { isolates to fosfomycin }\end{array}$} \\
\hline & 16 & 32 & 64 & 128 & 256 & 512 & 1026 \\
\hline \multicolumn{8}{|l|}{$\begin{array}{l}\text { ESBL producers } \\
N=319\end{array}$} \\
\hline $\begin{array}{l}\text { Escherichia coli* } \\
\mathrm{N}=216\end{array}$ & 0 & 0 & 0 & 0 & 0 & 0 & 0 \\
\hline $\begin{array}{l}\text { K.pneumoniae } \\
\mathrm{N}=49\end{array}$ & $14(30)$ & $14(30)$ & $14(30)$ & $14(30)$ & $10(20)$ & $6(12.2)$ & $2(4)$ \\
\hline $\begin{array}{l}\text { Pseudomonas } \operatorname{spp}^{\alpha} \\
\mathrm{N}=32\end{array}$ & $16(50)$ & $16(50)$ & $16(50)$ & $16(50)$ & $16(50)$ & $12(38.4)$ & $3(9)$ \\
\hline $\begin{array}{l}\text { Enterobacter } \operatorname{spp}^{\delta} \\
\mathrm{N}=22\end{array}$ & $15(68)$ & $10(45)$ & $10(45)$ & $9(40)$ & $9(40)$ & $5(22.7)$ & I (4) \\
\hline \multicolumn{8}{|l|}{$\begin{array}{l}\mathrm{MBL} \text { producers } \\
\mathrm{N}=138\end{array}$} \\
\hline $\begin{array}{l}\text { Escherichia coli* } \\
\mathrm{N}=44\end{array}$ & 0 & 0 & 0 & 0 & 0 & 0 & 0 \\
\hline $\begin{array}{l}\text { K.pneumoniae }{ }^{\#} \\
\mathrm{~N}=38\end{array}$ & $19(50)$ & $19(50)$ & $19(50)$ & $19(50)$ & $19(50)$ & 18 (47.3) & $4(10)$ \\
\hline $\begin{array}{l}\text { Pseudomonas } \text { spp }^{\alpha} \\
\mathrm{N}=32\end{array}$ & $16(50)$ & $16(50)$ & $16(50)$ & $16(50)$ & $16(50)$ & $12(37.5)$ & $3(9)$ \\
\hline $\begin{array}{l}\text { Enterobacter } \operatorname{spp}^{\delta} \\
\mathrm{N}=20\end{array}$ & $9(45)$ & $9(45)$ & $9(45)$ & $9(45)$ & $8(40)$ & $8(40)$ & $2(10)$ \\
\hline \multicolumn{8}{|l|}{$\begin{array}{l}\text { AmpC BL } \\
\text { Producers } N=158\end{array}$} \\
\hline $\begin{array}{l}\text { Escherichia coli* } \\
N=64\end{array}$ & 0 & 0 & 0 & 0 & 0 & 0 & 0 \\
\hline $\begin{array}{l}\text { K.pneumoniae }{ }^{\#} \\
\mathrm{~N}=38\end{array}$ & $16(42)$ & $16(42)$ & $16(42)$ & $15(39)$ & $10(26)$ & $10(26)$ & $3(8)$ \\
\hline $\begin{array}{l}\text { Pseudomonas spP }{ }^{\alpha} \\
\mathrm{N}=32\end{array}$ & $16(50)$ & $16(50)$ & $16(50)$ & $16(50)$ & $16(50)$ & $12(37.5)$ & $3(9)$ \\
\hline $\begin{array}{l}\text { Enterobacter } \operatorname{spp}^{\delta} \\
\mathrm{N}=20\end{array}$ & $8(40)$ & $8(40)$ & $8(40)$ & $8(40)$ & $6(30)$ & $4(20)$ & I (5) \\
\hline
\end{tabular}

Notes: *For Escherichia coli the MIC of fosfomycin according to CLSI (S $\leq 64 \mu \mathrm{gm} / \mathrm{mL}, \mathrm{I}=128 \mu \mathrm{gm} / \mathrm{mL}$. R $>256 \mu \mathrm{gm} / \mathrm{mL})$. The MIC 50 and MIC 90 of fosfomycin in Escherichia coli was I $\mu \mathrm{gm} / \mathrm{mL}$ and $2 \mu \mathrm{gm} / \mathrm{mL}$ respectively. ${ }^{\#}$ For Klebsiella pneumoniae the MIC of fosfomycin according to EUCAST interpretative criteria (S $\left.\leq 32, \mathrm{R}>32\right)$. The MIC50 and MIC 90 of fosfomycin in Klebsiella pneumoniae was $32 \mu \mathrm{gm} / \mathrm{mL}$ and $1026 \mu \mathrm{gm} / \mathrm{mL}$ respectively. ${ }^{\alpha}$ For Pseudomonas aeruginosa the MIC of fosfomycin according to EUCAST interpretative criteria (S $\leq 32, \mathrm{R}>32$ ). The MIC50 and MIC 90 of fosfomycin in Pseudomonas aeruginosa was $32 \mu \mathrm{gm} / \mathrm{mL}$ and $1026 \mu \mathrm{gm} / \mathrm{mL}$ respectively. ${ }^{\delta}$ For Enterobacter spp the MIC of fosfomycin according to EUCAST interpretative criteria (S $\leq 32, \mathrm{R}>32)$. The MIC50 and MIC 90 of fosfomycin in Enterobacter spp was $32 \mu \mathrm{gm} / \mathrm{mL}$ and $1026 \mu \mathrm{gm} / \mathrm{mL}$ respectively.

identified from different wards included in the study. Most of the MDR isolates included in the study were from patients with complicated UTI in the form of catheterization or associated diabetes mellitus, renal calculi or posturological procedures (Table 1). In this context, MDR isolates being more commonly isolated from catheterized individuals could be a reflection of colonization and some may be due to catheter-associated UTI, though this was not determined in the study.
We observed that almost all the isolates which were obtained from patients admitted in the various departments included in the study showed variable but high resistance to most of the antibiotics while most remained sensitive to fosfomycin (Table 2). Among all isolates, Escherichia coli $(100 \%)$ seemed to be the most susceptible to fosfomycin followed by Klebsiella spp (70\%), and Enterobacter spp (60\%). Other UTI pathogens like Pseudomonas spp also showed moderate (50-60\%) susceptibility to fosfomycin 
Table 4 Effect of fosfomycin on different multidrug resistant isolates

\begin{tabular}{|c|c|c|c|c|c|c|}
\hline \multirow{2}{*}{$\begin{array}{l}\text { MDR isolates } \\
\text { Total } N=326\end{array}$} & \multicolumn{6}{|c|}{ MIC of Fosfomycin [ $\mathrm{\mu gm} / \mathrm{mL}]$ (\%) } \\
\hline & 16 & 32 & 64 & 128 & 256 & 512 \\
\hline $\begin{array}{l}\text { Escherichia coli* } \\
\mathrm{N}=217\end{array}$ & 0 & 0 & 0 & 0 & 0 & 0 \\
\hline $\begin{array}{l}\text { K.pneumoniae } \\
\mathrm{N}=52\end{array}$ & $18(35)$ & $18(35)$ & $18(35)$ & $18(35)$ & II (20) & $6(12.2)$ \\
\hline $\begin{array}{l}\text { Pseudomonas spp } \\
\mathrm{N}=32\end{array}$ & $16(50)$ & $16(50)$ & $16(50)$ & $16(50)$ & $16(50)$ & $12(38.4)$ \\
\hline $\begin{array}{l}\text { Enterobacter } \text { spp }^{\delta} \\
\mathrm{N}=25\end{array}$ & $15(59.5)$ & $10(40)$ & $10(40)$ & $10(40)$ & $9(36)$ & $9(36)$ \\
\hline
\end{tabular}

Notes: *For Escherichia coli the MIC of fosfomycin according to CLSI (S $\leq 64 \mu \mathrm{gm} / \mathrm{mL}, \mathrm{I}=128 \mu \mathrm{gm} / \mathrm{mL}$. R> $256 \mu \mathrm{gm} / \mathrm{mL})$. The MIC 50 and MIC 90 of fosfomycin in Escherichia coli was $1 \mu \mathrm{gm} / \mathrm{mL}$ and $2 \mu \mathrm{gm} / \mathrm{mL}$ respectively. ${ }^{\#}$ For Klebsiella pneumoniae the MIC of fosfomycin according to EUCAST interpretative criteria (S $\leq 32$, R>32). The MIC50 and MIC 90 of fosfomycin in Klebsiella pneumoniae was $32 \mu \mathrm{gm} / \mathrm{mL}$ and $1026 \mu \mathrm{gm} / \mathrm{mL}$ respectively. ${ }^{\alpha}$ For Pseudomonas aeruginosa the MIC of fosfomycin according to EUCAST interpretative criteria $(\mathrm{S} \leq 32, \mathrm{R}>32)$. The MIC50 and MIC 90 of fosfomycin in Pseudomonas aeruginosa was $32 \mu \mathrm{gm} / \mathrm{mL}$ and $1026 \mu g m / \mathrm{mL}$ respectively. $\delta$ ForEnterobactersppthe MIC of fosfomycin according to EUCAST interpretative criteria ( $\leq 32, \mathrm{R}>32)$. The MIC50 and MIC 90 of fosfomycin in Enterobacter spP was $32 \mu \mathrm{gm} / \mathrm{mL}$ and $1026 \mu \mathrm{gm} / \mathrm{mL}$ respectively.

Table 5 Effect of fosfomycin on biofilm produced by different isolates

\begin{tabular}{|c|c|c|c|c|c|}
\hline $\begin{array}{l}\text { S } \\
\text { NO }\end{array}$ & Isolate & $\begin{array}{l}\text { Overall inhibited } \\
\text { (\%) }\end{array}$ & $\begin{array}{l}\text { Biofilm inhibi- } \\
\text { tion exclusively } \\
\text { at } 16 \mathrm{hrs}(\%)\end{array}$ & $\begin{array}{l}\text { Biofilm inhibi- } \\
\text { tion exclusively } \\
\text { at } 24 \mathrm{hrs}(\%)\end{array}$ & $\begin{array}{l}P \text {-value indicating the difference between } \\
\text { biofilm inhibition at } 16 \mathrm{hrs} \text { and at } 24 \mathrm{hrs} \\
\text { exposure to fosfomycin }\end{array}$ \\
\hline I & $\begin{array}{l}\text { Escherichia coli } \\
\mathrm{N}=|4| / 2 \mid 7\end{array}$ & $96 / 141(67)$ & $76(53)$ & $20(14)$ & $P<0.0001$ \\
\hline 2 & $\begin{array}{l}\text { K.pneumoniae } \\
\mathrm{N}=50 / 52\end{array}$ & $37 / 50(74)$ & $22(44)$ & $15(30)$ & $P<0.0001$ \\
\hline 3 & $\begin{array}{l}\text { Pseudomonas spp } \\
N=27 / 32\end{array}$ & $24 / 27(88)$ & $12(44)$ & $12(44)$ & $P<0.0001$ \\
\hline \multirow[t]{2}{*}{4} & $\begin{array}{l}\text { Enterobacter spp } \\
\mathrm{N}=23 / 25\end{array}$ & $10 / 23(36)$ & $5(18)$ & $5(18)$ & $P=0.068$ \\
\hline & Total & $|67 / 24|(69.2)$ & || $5 / 24 \mid(47.7)$ & $52 / 24 \mid(21.5)$ & $P<0.001$ \\
\hline
\end{tabular}

(Table 2). In a study done by Falagas et al and Maraki et al, in Greece have also shown very encouraging susceptibility results similar to this study. In the study by Maraki et al, reported fosfomycin was active in vitro against a majority percentage of urinary isolates, which showed high antimicrobial resistance against the most commonly used agents for the treatment of UTIs. ${ }^{13}$ In another study by Mittal et al, all uropathogenic Escherichia coli strains were found to be sensitive to fosfomycin. According to Rajendran et al, fosfomycin was the only antibiotic that effectively inhibited $90 \%$ of the strains of Escherichia coli and Klebsiella spp . ${ }^{14}$

Of the 326 isolates, $319(97.8 \%)$ were resistant to the third generation cephalosporins and were also extended- spectrum beta-lactamases (ESBL) producers (Table 3). All these isolates were sensitive to fosfomycin (Table 3). In an earlier study done by Gupta et al from Chandigarh, among 150 uropathogenic strains of Escherichia coli, 52.6\% of isolates were ESBL producers, and all strains were susceptible to fosfomycin. ${ }^{15}$ An increasing trend of ESBL producers has been observed from India, which is attributable to the irrational use and ease of availability of antibiotics over the counter and such isolates are prevalent among hospitals as well as in the community. ${ }^{16}$ In a study done by Cueto et al, also demonstrated 428 ESBL producing Escherichia coli and Klebsiella pneumoniae strainswere exposed to fosfomycin and it showed high in vitro activity against all these strains. ${ }^{17}$ 
In comparison to the ESBLs, AmpC beta-lactamases are known to be notorious, as they hydrolyze not only the third generation cephalosporins (3GCs) but also beta-lactamase inhibitor plus beta-lactam combinations. Though carbapenems are the drug of choice against these organisms fosfomycin has been found to be effective in vitro in earlier studies. ${ }^{13,18}$ Fosfomycin showed a similar effect on AmpC BL producing Escherichia coli (100\%), (57\%) in Enterobacter spp, and $(38 \%)$ in Klebsiella pneumoniae. It also inhibited AmpCBL Pseudomonas spp (30\%) (Table 3). Karlowsky et al too reported $99.4 \%$ fosfomycin susceptibility against urinary isolates of Escherichia coli, collected from 2010 to 2013 as a part of the Canadian national surveillance study. ${ }^{19}$ Beta-lactamaseproducing isolates and $\mathrm{AmpC}$-producing isolates of $E$. coli showed $94.9 \%$ and $96.6 \%$ susceptibility respectively. ${ }^{19}$

Carbapenemase-producing Enterobacteriaceae (CRE) is a major threat across the globe. ${ }^{20}$ In vitro effect of fosfomycin has been documented on some CRE isolates in an earlier study. ${ }^{21}$ In our study, fosfomycin showed a similar inhibitory effect on carbapenemase producing Escherichia coli (100\%), $50 \%$ each in Klebsiella pneumoniae and Enterobacter spp, while it inhibited $30 \%$ of the isolates of Pseudomonas spp (Table 3). In a study done by Banerjee et al in a 380 bedded tertiary care hospital in Kolkata, similar results with $89 \%$ inhibition with fosfomycin on CRE isolates were observed. ${ }^{22}$

Of 217 Escherichia coli MDR isolates included in the study, 78 (35.9\%) and 207 (95.4\%) were resistant to amikacin and gentamicin respectively, while fosfomycin showed $100 \%$ inhibition in vitro against these isolates (Table 4). On the other hand, fosfomycin inhibited $60 \%$ of MDR Klebsiella pneumoniae and Enterobacter spp which were (94\%) resistant to both aminoglycosides while fosfomycin inhibited $50 \%$ of Pseudomonas spp that are resistant to aminoglycosides (Table 4). Fosfomycin showed a similar inhibitory effect on Escherichia coli (100\%), 60\% each in Klebsiella pneumoniae and Enterobacter spp, while it inhibited 50\% of the isolates of Pseudomonas spp that were (98\%) resistant to fluoroquinolones (Table 4).

In contrary to a study done elsewhere, ${ }^{23}$ our observation showed good in vitro susceptibility to fosfomycin and nitrofurantoin against ESBL producing Escherichia coli, ESBL producing Klebsiella pneumoniae, similar to studies published earlier. ${ }^{23-27}$ Out of the total of 326 MDR isolates which were resistant to at least three (or more) groups of antibiotics thatareaminoglycosides, fluoroquinolones, and third-generationcephalosporins, $264(87.3 \%)$ were susceptible to fosfomycin which suggests that this could be the drug of choice against such resistant isolates (Table 3). In the present study, we observed fosfomycin at a concentration of $32 \mu \mathrm{gm} / \mathrm{mL}$ could inhibit the $2 \%$ of isolates and $20 \%$ of isolates at $12 \mathrm{hrs}$ and $24 \mathrm{hrs}$ respectively, while $64 \mu \mathrm{gm} / \mathrm{mL}$ of fosfomycin was able to inhibit $24 \%$ of isolates and $36 \%$ of isolates at $12 \mathrm{hrs}$ and $24 \mathrm{hrs}$ respectively. The difference between the inhibition at $12 \mathrm{hrs}$ and at $24 \mathrm{hrs}$ by fosfomycin at both these concentrations (32 $\mu \mathrm{gm} / \mathrm{mL}$ and $64 \mu \mathrm{gm} / \mathrm{mL}$ ) was found to be statistically significant with $(P=0.001)$ and $(P=0.03)$ respectively. This in vitro observation supports the fact that prolonged duration of exposure to fosfomycin at $32 \mu \mathrm{gm} / \mathrm{mL}$ in urine can enhance the bactericidal effect thereby, further aiding clinical cure.

As a result of increased incidence and chronicity of biofilm infections, newer strategies are being developed which has a capability to reduce the incidence of biofilm infections and effectively helps in treating this chronic conditions related to the establishment of these difficult-to-eradicate bacterial structures. In this regard, the effect of fosfomycin on biofilm was studied. Due to its good renal excretion, fosfomycin getsconcentrated in urine which enhances its ability to break up biofilms. ${ }^{28}$ In this present study, out of 326 isolates, 218 (66.87\%) isolates produced biofilm which was detected by tissue culture plate method. Similar to the study by Christensen et $\mathrm{al}^{29}$ fosfomycin could disrupt biofilms at a concentration below the MIC. In the present study, we observed a similar inhibition of biofilm formation (Table 5). Fosfomycin disrupted biofilm produced by 115 (38\%) strains exclusively at $16 \mathrm{hrs}$ of incubation and 167 (69.2\%) strains at $24 \mathrm{hrs}$ of incubation. The difference of inhibition of biofilm formation in Escherichia coli and K.pneumoniae, and Pseudomonas spp at $16 \mathrm{hrs}$ and at $24 \mathrm{hrs}$ was statistically significant $(P$-value $<0.0001)$, unlike that ofEnterobacter spp. (Table 5). In a study done by Anna Marchese et al, it was found that fosfomycin alone and in combination with N-acetylcysteine showed a decrease in biofilm formation up to $60-73 \%$ Escherichia coli..$^{30}$ Further, a study was done by Cai et al with fosfomycinina combination of aminoglycosides showed a decrease in biofilm formation in vitro and in vivo. ${ }^{28}$ Fosfomycin also has antimicrobial action against gram-positive bacteria and decrease biofilm in Staphylococcus aureus. ${ }^{31}$ They also suggested that bacterial biofilms that are formed in vivo appear to be more easily destroyed by antibiotics than biofilms established on the surface of catheters. ${ }^{31}$ Fosfomycin was capable of inhibiting biofilm formation in $88 \%$ Pseudomonas isolates, in $74 \%$ Klebsiella pneumoniae, in 68\% Escherichia coli and 43\% Enterobacter spp (Table 5). The basis of this inhibition is still not very clear and in-depth analysis at the molecular level needs to be undertaken to unravel the mechanisms involved. 
In recent years, multidrug resistance has emerged rapidly among diverse bacterial types as a consequence of irrational antibiotic use in agriculture and human and veterinary medicine. Risk factors like catheterization, diabetes mellitus, renal calculi and urological procedures with structural and functional abnormalities increase the risk of acquiring urinary tract infections with multidrug resistance strains which further increases morbidity and mortality. ${ }^{32}$ Treatment of such infections relies on the use of broadspectrum antibiotics like carbapenems, tigecycline, betalactam/beta-lactamase inhibitor combinations. The use of such antibioticsis weakened by various factors such as their parenteral route of administration which is not feasible in an outdoor setting, high cost and their added effect on the selective pressure to develop resistance. Thus, there is definitely a need for a newer drug that is orally active, has low levels of existing multi drug resistance and also doesn't encourage the emergenceof antimicrobial resistance in the future. Fosfomycin is an old antibiotic with good in vitro activity against the common pathogens causing UTI, particularly toward the Enterobacteriaceae acts by inactivating the enzyme that is required for peptide portion of peptidoglycan, thus disrupting bacterial cellwall synthesis. This antibiotic has the potential to be used as an agent to treat uncomplicated UTIs. There are increasing reports of its resistance in countries where it has been used extensively such as Spain and Hong Kong, hence, caution needs to be exercised over its use. ${ }^{33}$ Resistance to fosfomycinin Enterobacteriaceae is more commonly chromosomally encoded than by plasmids. However, co-transmission of resistance to fosfomycin and resistance to other antimicrobials through plasmids has been shown but are very rare. ${ }^{34}$ Nevertheless, monotherapy of fosfomycin is not recommended as the development of resistance during therapy is a serious concern. ${ }^{35}$

\section{Limitations of the present study}

Most of the MDR isolates were from Enterobacteriaceae with a limited number of Pseudomonas aeruginosa. We did not study the clinical outcome with the antibiotic therapy and also, the genetic mechanism of resistance of these MDR isolates was not studied since these were not a focus of this study. The exact molecular basis of this biofilm reduction contributed by fosfomycin needs to be studied in detail.

\section{Conclusion}

In this study, we observed that fosfomycin has a good in vitro effect on most of the MDR gram-negativebacteria. It showed significantly goodactivity against ESBL, AmpC BL producing Escherichia coli, MBL producers like Pseudomonas aeruginosa and Klebsiella pneumoniae. Fosfomycin also had good activity on biofilm producing strains studied here. Further clinical studies using fosfomycin will add data to support fosfomycin its use in the treatment of urinary tract infections due to MDR pathogens which have the capacity to form a biofilm. Also, in-depth studies to understand the mechanism of biofilm inhibition are required.

\section{Ethics clearance}

Study was approved by the scientific advisory committee and the ethicscommittee of the Institute (NO. JIP/IEC/SC/2015/ 23/831). Written Informed consent was obtained from the patients prior to the collection of clinical and demographic details as per the ethicscommittee of the Institute.

\section{Disclosure}

This study is not submitted to any government departments or granting bodies. The authors do not own any stocks or shares in a company from which we procured the drug. The authors did not accept any reimbursement for preparing this article. The authors report no conflicts of interest in this work.

\section{References}

1. Levison ME, Kaye D. Treatment of complicated urinary tract infections with an emphasis on drug-resistant gram-negative uropathogens. Curr Infect Dis Rep. 2013;15(2):109-115. doi:10.1007/s11908-013-0315-7

2. Falagas ME, Polemis M, Alexiou VG, Marini-Mastrogiannaki A, Kremastinou J, Vatopoulos AC. Antimicrobial resistance of Esherichiacoli urinary isolates from primary care patients in Greece. Med Sci Monit. 2008;14(2):CR75-79.

3. Gupta N, Limbago BM, Patel JB, Kallen AJ. Carbapenem-resistant Enterobacteriaceae: epidemiology and prevention. Clin Infect Dis. 2011;53(1):60-67. doi:10.1093/cid/cir202

4. Prigent-Combaret C, Brombacher E, Vidal O, et al. Complex regulatory network controls initial adhesion and biofilm formation in Escherichia coli via regulation of the csgDGene. $J$ Bacteriol. 2001;183(24):7213-7223. doi:10.1128/JB.183.24.7213-7223.2001

5. Keating GM. Fosfomycintrometamol: a review of its use as a singledose oral treatment for patients with acute lower urinary tract infections and pregnant women with asymptomatic bacteriuria. Drugs. 2013;73(17):1951-1966. doi:10.1007/s40265-013-0143-y

6. Auer S, Wojna A. Oral treatment options for ambulatory patients with urinary tract infections caused by extended-spectrum-beta-lactamaseproducing Escherichia coli. Antimicrob Agents Chemother. 2010:54 (9):4006-4008. Epub 2010 Jun 28. doi:10.1128/AAC.01760-09

7. Huttner A, Kowalczyk A, Turjeman A, et al. Effect of 5-day Nitrofurantoin vs Single-dose fosfomycin on clinicalResolution of uncomplicated lower urinary tract infection in women: a randomized clinical trial. JAMA. 2018;319(17):1781-1789. doi:10.1001/jama.2018.3627

8. Winn W, et al. Koneman's Color Atlas and Textbook of Diagnostic Microbiology. 6th ed. Baltimore, USA: Lippincot Williams \& Winkins; 2006:213-293. 
9. Winn W, et al. Koneman's Color Atlas and Textbook of Diagnostic Microbiology. 6th ed. Baltimore, USA: Lippincot Williams \& Winkins; 2006:309-355.

10. Performance Standards for Antimicrobial Susceptibility Testing; Twenty-Fourth Informational Supplement. Wayne, USA: CLSI; 2014.

11. European Committee on Antimicrobial Susceptibility Testing. 2015. Breakpoint tables for interpretation of MICs and zone diameter, version5.0. Avalible from: http://www.eucast.org/.last. Accessed September $5,2018$.

12. Schadow KH, Simpson WA, Christensen GD. Characteristics of adherence to plastic tissue culture plates of coagulase-negative staphylococci exposed to sub-inhibitory concentrations of antimicrobial agents. J Infect Dis. 1988;157(1):71-77. doi:10.1093/infdis/157.1.71

13. Maraki S, Samonis G, Rafailidis P, et al. Susceptibility of urinary tract bacteria to fosfomycin. Antimicrob Agents Chemother. 2009;53 (10):4508-4510. doi:10.1128/AAC.00721-09

14. Rajenderan S, Balaji V, Anandan S, Sahni RD, Tansarli GS, Falagas ME. Determination of MIC distribution of arbekacin, cefminox, fosfomycin, biapenem and other antibiotics against gram-negative clinical isolates in South India: a prospective study. PLoS One. 2014;9(7):e103253. doi:10.1371/journal.pone.0103253

15. Gupta V, Rani H, Singla N, Kaistha N, Chander J. Determination of extended-spectrum $\beta$-lactamases and ampcproduction in uropathogenicisolates of escherichiacoli and susceptibility to fosfomycin. $J$ Lab Physicians. 2013;5(2):90-93. doi:10.4103/0974-2727.119849

16. Bradford PA. Extended-spectrum beta-lactamases in the 21st century: characterization, epidemiology, and detection of this important resistance threat. Clin Microbiol Rev. 2001;14(4):933-951. doi:10.1128/ CMR.14.4.933-951.2001

17. De Cueto M, Lopez L, Hernandez JR, Morillo C, Pascual A. In vitro activity of fosfomycin against extended-spectrum- $\beta$-lactamase producing Escherichia coli and Klebsiellapneumoniae: comparison of susceptibility testing procedures. Antimicrob Agents Chemother. 2006;50 (1):368-370. doi:10.1128/AAC.50.1.368-370.2006

18. Gladstone P, Rajendran P, Brahmadathan KN. Incidence of carbapenem resistantnonfermentinggram negative bacilli from patients with respiratory infections in the intensive care units. Indian $\mathrm{J} \mathrm{Med}$ Microbiol. 2005;23(3):189-191.

19. Karlowsky JA, Denisuik AJ, Lagacé-Wiens PR, et al. In vitro activity of fosfomycin against Escherichia coli isolated from patients with urinary tract infections in Canada as part of the CANWARD surveillance study. Antimicrob Agents Chemother. 2014;58(2):1252-1256. doi:10.1128/AAC.02399-13

20. Rodríguez-Baño J, Gutiérrez-Gutiérrez B, Machuca I, Pascual A. Treatment of infections caused by extended-spectrum-beta-lactamase-, AmpC-, and carbapenemase-producing enterobacteriaceae. Clin Microbiol Rev. 2018;31(2):e00079-e000717. doi:10.1128/ CMR.00079-17

21. Livermore DM, Warner M, Mushtaq S, Doumith M, Zhang J, Woodford $\mathrm{N}$. What remains against carbapenem-resistant Enterobacteriaceae? Evaluation of chloramphenicol, ciprofloxacin, colistin, fosfomycin, minocycline, nitrofurantoin, temocillinandtigecycline. Int $J$ Antimicrob Agents. 2011;37(5):415-419. doi:10.1016/j.ijantimicag.2011.01.012
22. Banerjee S, Sengupta M, Sarker TK. Fosfomycin susceptibility among multidrug-resistant, extended-spectrum beta-lactamase-producing, carbapenem-resistant uropathogens. Indian J Urol. 2017;33 (2):149-154. doi:10.4103/iju.IJU_285_16

23. Shakti L, Veeraraghavan B. Advantage and limitations of nitrofurantoin in multi-drugresistantIndianscenario. Indian J Med Microbiol. 2015;33(4):477-481. doi:10.4103/0255-0857.167350

24. Meier S, Weber R, Zbinden R, Ruef C, Hasse B. Extended-spectrum $\beta$-lactamase-producing Gram-negative pathogens in communityacquired urinary tract infections: an increasing challenge for antimicrobial therapy. Infection. 2011;39(4):333-340. doi:10.1007/s15010011-0132-6

25. Tulara NK. Nitrofurantoin and Fosfomycin for extended spectrumbetalactamases producing Escherichia coli and Klebsiellapneumoniae. J Glob Infect Dis. 2018;10(1):19-21. doi:10.4103/jgid.jgid_72_17

26. Fransen F, Melchers MJ, Meletiadis J, Mouton JW. Pharmacodynamics and differential activity of nitrofurantoin against ESBL-positive pathogens involved in urinary tract infections. J Antimicrob Chemother. 2016;71 (10):2883-2889. doi:10.1093/jac/dkw212

27. Huttner A, Verhaegh EM, Harbarth S, Muller AE, Theuretzbacher U, Mouton JW. Nitrofurantoin revisited: a systematicreview and metaanalysis of controlledtrials. J Antimicrob Chemother. 2015;70 (9):2456-2464. doi:10.1093/jac/dkv147

28. Cai Y, Fan Y, Wang R, An MM, Liang BB. Synergistic effects of aminoglycosides and fosfomycin on Pseudomonas aeruginosa in vitro and biofilm infections in a rat model. J Antimicrob Chemother. 2009;64(3):563-566. doi:10.1093/jac/dkp224

29. Christensen GD, Simpson WA, Younger JJ, et al. Adherence of coagulase-negative staphylococci to plastic tissue culture plates: a quantitative model for the adherence of staphylococci to medical devices. J.Clin.Microbiol. 1985;22:996-1006.

30. Marchese A, Bozzolasco M, Gualco L, Debbia EA, Schito GC, Schito AM. Effect of fosfomycin alone and in combination with $\mathrm{N}$-acetylcysteine on E. coli biofilms. Int J Antimicrob Agents. 2003;22(Suppl 2):95-100.

31. Chai D, Liu X, Wang R, Bai Y, Cai Y. Efficacy of linezolid and fosfomycin in catheter-related biofilm infection caused by methicillin-resistant staphylococcus aureus. Biomed Res Int. 2016;2016:6413982. doi:10.1155/2016/6413982

32. Johnson JR, Delavari P, Azar M. Activities of a nitrofurazone-containing urinary catheter and a silver hydrogel catheter against multidrug-resistant bacteria characteristic of catheter-associated urinary tract infection. Antimicrob Agents Chemother. 1999;43(12):2990-2995.

33. Giske CG. Contemporaryresistancetrends and mechanisms for the oldantibioticscolistin, temocillin, fosfomycin, mecillinam and nitrofurantoin. Clin Microbiol Infect. 2015;21(10):899-905. doi:10.1016/j. cmi.2015.05.022

34. Li Y, Zheng B, Li Y, Zhu S, Xue F, Liu J. Antimicrobial susceptibility and molecular mechanisms of fosfomycin resistance in clinical escherichia coli isolates in mainland China. PLoS One. 2015;10(8): e0135269. doi:10.1371/journal.pone.0135269

35. Hardisson C, Villar CJ, Llaneza J, Mendoza MC. Prevalence and dispersion of plasmidsconferringfosfomycinresistance in enterobacteria. Pathol Biol (Paris). 1984;32(7):755-758.

Infection and Drug Resistance

Dovepress

\section{Publish your work in this journal}

Infection and Drug Resistance is an international, peer-reviewed openaccess journal that focuses on the optimal treatment of infection (bacterial, fungal and viral) and the development and institution of preventive strategies to minimize the development and spread of resistance. The journal is specifically concerned with the epidemiology of

antibiotic resistance and the mechanisms of resistance development and diffusion in both hospitals and the community. The manuscript management system is completely online and includes a very quick and fair peerreview system, which is all easy to use. Visit http://www.dovepress.com/ testimonials.php to read real quotes from published authors.

Submit your manuscript here: https://www.dovepress.com/infection-and-drug-resistance-journa 